\title{
Risk Adjusted Production Efficiency of Maize Farmers in Ethiopia: Implication for Improved Maize Varieties Adoption
}

\author{
Sisay Diriba Lemessa ${ }^{1 *}$, Molla Alemayehu Yismawu ${ }^{1}$, Megersa Debela Daksa ${ }^{1}$, \\ Mulugeta Damie Watabaji ${ }^{2}$
}

${ }^{1}$ Department of Economics, College of Business and Economics, Haramaya University, -138, Dire Dawa, Ethiopia ${ }^{2}$ College of Agricultural Economics and environmental sciences, Haramaya University, -138, Dire Dawa, Ethiopia A R T I C L E I N F O

\section{Research Article}

Received 17 May 2017 Accepted 13 July 2017

Keywords:

Technical efficiency

Production risk

Maize farms

Ethiopia

Stochastic Frontier

*Corresponding Author:

E-mail: sis.milly@gmail.com \begin{abstract}
A B S T R A C T
This study analyzes the technical efficiency and production risk of 862 maize farmers in major maize producing regions of Ethiopia. It employs the stochastic frontier approach (SFA) to estimate the level of technical efficiencies of stallholder farmers. The stochastic frontier approach (SFA) uses flexible risk properties to account for production risk. Thus, maize production variability is assessed from two perspectives, the production risk and the technical efficiency. The study also attempts to determine the socio-economic and farm characteristics that influence technical efficiency of maize production in the study area. The findings of the study showed the existence of both production risk and technical inefficiency in maize production process. Input variables (amounts per hectare) such as fertilizer and labor positively influence maize output. The findings also show that farms in the study area exhibit decreasing returns to scale. Fertilizer and ox plough days reduce output risk while labor and improved seed increase output risk. The mean technical efficiency for maize farms is 48 percent. This study concludes that production risk and technical inefficiency prevents the maize farmers from realizing their frontier output. The best factors that improve the efficiency of the maize farmers in the study area include: frequency of extension contact, access to credit and use of intercropping. It was also realized that altitude and terracing in maize farms had influence on farmer efficiency.
\end{abstract}

DOI: https://doi.org/10.24925/turjaf.v5i9.1099-1107.1339

\section{Introduction}

Agriculture is the mainstay of Ethiopian economy as it accounts for 49 percent of the country's Gross Domestic Product (GDP), 95 percent of export earnings, and 85 percent of employment generation (CSA, 2013). Despite the availability of greater potential, Ethiopia's agricultural productivity is low. Among other factors, the low productivity can be attributed to climate changes (Virtanen et al., 2001), inappropriate economic policies and low adoption rate of improved agricultural technologies (Abdulahi, 2005; Sanchez et al., 2009; Teklewold et al., 2013). The fast-growing population outstripping the agricultural output growth is another driving force for the increased agricultural productivity in Ethiopia. This calls for improvement in agricultural productivity to alleviate poverty and to tackle food insecurity problem in Ethiopia.

Maize is an important staple food crop in Ethiopia. It is a dominant crop that accounts for over 16 percent and 26 percent of the total cultivated land and cereal production, respectively (CSA, 2014). With 8.8 million maize growing farmers, maize is also one of the most important crops in terms of number of small-to-mediumscale growers, compared with 6.6 million growers for teff
(Teff is a fine grain-about the size of a poppy seed-that comes in a variety of colors, from white and red to dark brown. Teff grows predominantly in Ethiopia and Eretria, and thrives even in difficult climates) and 4.7 million growers for wheat. In terms of volume of production, maize is ranked first with 6.5 million metric tons (MT) in 2013/14, followed by teff with 4.4 million MT, wheat with 3.9 million MT and sorghum with 3.8 million MT, respectively. As such, maize continues to be a significant contributor to the national economic and social development and is viewed as a key crop for livelihood strategies of smallholder farmers (CSA, 2014).

In Ethiopia, Maize farming is characterized by stagnation and volatility in production and productivity for decades though there is an increase in total maize production over the years. The increase in maize production comes predominantly from area expansion as the uses of yield-boosting technologies by farmers are limited. The low maize yield shows the existence of a scope for optimization of maize production through use of technology and efficient allocation of resources.

Studies of technical efficiency in agricultural production in developing countries have proliferated in 
recent years, as it contributes to a much better understanding of its causes and extent. However, the difference between technical inefficiencies that resulted from limitations in the farming practices and from riskaverse behavior of farmers is not widely studied.

Limited studies conducted in Ethiopia to estimate the technical efficiency of maize farmers using conventional estimation of stochastic frontier analysis (Aynalem, 2006; Tesfaye and Hassen, 2014) failed to account for risk in the production process which results in biased estimates of technical efficiency (Villano and Fleming, 2006). That is the extent of technical inefficiency may have been substantially overstated in studies of farm performance in risky production environments. Moreover in Ethiopia, there is no a comprehensive study conducted to analyze the technical efficiency of maize farms that inculcate the effect of production risk.

The aim of this study is therefore to estimate the technical efficiency of maize farms whilst incorporating a risk component in Ethiopia. Incorporating the production risk helps to obtain unbiased estimates of technical efficiency of maize farms. It also investigates production risk, technical efficiency, and factors associated to maize production of smallholder farmers in three regions of Ethiopia namely: Oromia, Southern Nations, Nationalities and Peoples (SNNP), and Benishangul Gumuz. The study adopts the stochastic frontier approach (SFA) with flexible risk properties to estimate the level of technical efficiencies that accounts for production risk. Thus, maize production variability is assessed from two perspectives, production risk and technical efficiency. Single stage maximization likelihood estimation is used to provide the estimates of the mean output, production risk and technical efficiency models.

The remaining parts of the paper are organized as follows: Section 2 presents the methods used for data collection and estimation of the technical efficiency and production risk. Results and discussions are presented in section 3 and finally section 4 provides the conclusions and policy implications.

\section{Materials and Methods}

The data used in this study were collected by the Ethiopian Institute of Agricultural Research (EIAR) in collaboration with the International Maize and Wheat Improvement Center (CIMMYT) using structured questionnaire administered to farm households.

The survey covered the 2009/10 agricultural season in the Oromia, Benishangul Gumuz, and Southern Nations, Nationalities, and People (SNNP) regions in Ethiopia. The regions are known of maize-legume based farming systems in the country. Maize-legume farming packages considered by EAIR and CIMMYT include maize-legume rotation, improved maize varieties, and conservation tillage, complemented with the use of animal manure and inorganic fertilizer. Data collection took place between October and December, 2010. Sample of 684 maize farmers in the three regions of Ethiopia were used for this study.
The stochastic frontier approach (SFA), based on a specific functional form which is introduced by Aigner et al. (1977) and Meeusen (1977) is used to analysis data. This is motivated by the idea that deviations from the frontier may not be entirely attributed to inefficiency alone. This is due to an argument that random shocks that are beyond the control of farmers can also affect the output.

As the conventional SFA does not adequately address production risk, using it will result in biased estimates of technical efficiency. This model proposes that inputs have similar effect on mean and variances of maize outputs. However, Meeusen et al. (1977) proposed a production function that has separate effects of the inputs on the mean and variance of outputs whilst Kumbhakar (2002) further incorporates technical inefficiency model. This study, therefore, employed the stochastic frontier model with flexible risk properties to estimate the level of technical efficiencies that account for production risk. Following Kumbhakar (2002) the production process is represented below as:

$$
Y_{i}=f\left(X_{i} ; \beta\right)+\varepsilon_{i}
$$

Where $Y_{i}$ is observed maize output of the $\mathrm{i}^{\text {th }}$ farmer, $X_{i}$ is level of inputs used by $\mathrm{i}^{\text {th }}$ farmer, $\beta$ is the estimated coefficient of the output function and $\varepsilon_{i}$ is the error term that can take different specification depending on the nature of the specified analytical model. Following the standard SFA, the error term $\varepsilon_{i}$ in equation 1 is composed of two independent elements:

$$
\varepsilon_{i}=V_{i}-U_{i}
$$

Where $V_{i}$ is the risk and $U_{i}$ is the inefficiency

Re-arranging the above equation can be written as

$$
\varepsilon_{i}=g\left(X_{i} ; \alpha\right) V_{i}-h\left(X_{i} ; \delta\right) U_{i}
$$

Where $g\left(X_{i} ; \alpha\right) V_{i}$ is the risk function, $h\left(X_{i} ; \delta\right) U_{i}$ is the inefficiency function, $\alpha$ and $\delta$ are the parameter vectors. The random factors outside the farmer's control that affects maize production and other statistical noise are also captured by $U_{i}$ which is symmetric. The error term is assumed to be independently, identically, and normally distributed as $\operatorname{Nid}\left(0, \delta_{U}^{2}\right)$.

Producers with zero deviations are efficient producers that lie on the efficiency frontier while those with positive deviations lie below the efficiency frontier and are inefficient (Bachewe, 2009). Technical efficiency (TE) measures the output of producer i relative to the output that could be produced by a fully efficient producer using the same input vector (Coelli et al., 2005). The TE of producer $\mathrm{i}$, is therefore, estimated as the ratio of the actual output relative to the frontier output, as specified by Coelli et al. (2005):

$$
T E_{i}=\frac{Y_{i}}{e^{\left(X_{i} \beta+V_{i}\right)}}=e^{\left(-U_{i}\right)}=\frac{f\left(X_{i}, \beta\right)-g\left(X_{i}, \delta\right) U_{i}}{f\left(X_{i}, \beta\right)}=1-\frac{g\left(X_{i}, \delta\right) U_{i}}{f\left(X_{i}, \beta\right)}
$$


Where $Y_{i}=e^{\left(X_{i} \beta+V_{i}-U_{i}\right)}$ is the actual maize output which is obtained in the presence of the technical inefficiency effects,

$$
e^{\left(X_{i} \beta+V_{i}\right)}=\frac{g\left(X_{i}, \delta\right) U_{i}}{f\left(X_{i}, \beta\right)}
$$

is the corresponding frontier output under condition of random shocks (Coelli et al., 2005). When Dividing the actual maize output by the frontier output, the remaining $\left(-U_{i}\right)$ represent technical efficiency which takes values between zero and one. Technical efficiency takes a value of one when producers are technically efficient, moves towards zero when producers are less technically efficient and are zero when producers are fully inefficient (Bachewe, 2009).

Maize production risk variance is given as:

$$
\operatorname{Var}\left(Y_{i}\right)=g^{2}\left(X_{i}, \delta\right)
$$

In this study, there are input variables included which are supposed to affect maize output. The marginal effect of the input variables on the maize production risk is given as;

$$
\frac{\partial \operatorname{Var}\left(Y_{i}\right)}{\partial X_{i}}=\frac{2 g\left(X_{i}, \delta\right)}{\partial X_{i}}
$$

Where; $\left(2 g\left(X_{-} i, \delta\right)\right) /\left(\partial X_{-} i\right)>0$, the $\mathrm{i}^{\text {th }}$ input is a risk increasing input, but if,$\left(2 g\left(X_{-} i, \delta\right)\right) /\left(\partial X_{-} i\right)<0$ the $i^{\text {th }}$ input is a risk decreasing input while if $\left(2 g\left(X_{-} i, \delta\right)\right) /\left(\partial X_{-} i\right)=0$, then the $\mathrm{i}^{\text {th }}$ input is a risk neutral input.

A risk-averse farmer thus uses more of a risk reducing input than a risk neutral farmer (Pope and Kramer, 1979). Some inputs may reduce the level of output risk (e.g. pesticides) while others may increase risk (Asche and Tveteras, 1999). The first attempt to separate the effect of the inputs on the mean output and the variance of output or output risk was introduced by Just and pope (1978). Following Battese and Coelli (1995) the distributional assumption of the real-random-errors of a log likelihood function for the observed farm output is parameterized in terms of the variances. Therefore, tests for the presence of technical inefficiency are based on the variance parameters. The total variance consists of a variance due to random effects and a variance due to technical inefficiency effects which is parameterized as $\delta^{2}=$ $\delta v^{2}+\delta u^{2}$. The estimated variance parameters $(\rho)$ are used to identify the parameter which represents the proportion of total model variance that accounts for technical inefficiency. The parameterization of variance is given by Battese and Coelli (1995) that takes the form:

$$
\rho=\frac{\delta u^{2}}{\delta v^{2}}
$$

We find that the Cobb-Douglas production frontier best fits over that of the transcendental logarithmic (trnaslog) production frontier for the mean output function. Thus, this study estimates the parameters using a
Cobb-Douglas stochastic frontier. Assuming that producers are producing a single output (maize) using multiple inputs, the SFA provides the relative frontier against which production performance is evaluated (Kumbhakar and Lovell, 2000). A Cobb- Douglas stochastic production frontier given by Battese and Coelli (1995) for cross-sectional data takes the form:

$$
\begin{aligned}
& Y=\beta_{0} \prod_{n=1}^{N} X^{\beta_{0}} \\
& \ln Y_{i}=\beta_{0}+\sum_{j=1}^{N} \beta_{j} \ln X_{I J}+V_{I}+U_{I}
\end{aligned}
$$

Where: $Y_{i}$ is the log of maize output in ton per hectare (ton/ha) for $i^{\text {th }}$ farmer; $X$ is a vector of production inputs in logarithmic form.

The following hypothesis were formulated, first to ascertain the appropriateness of the functional form for the data, second to determine whether production risk in inputs and technical inefficiency significantly explain output variability, third to examine whether the exogenous variables and the conventional input variables in the technical efficiency model explains the technical inefficiency, and fourth, to examine whether there is regional effect on technical efficiency of production.

- $H_{0}: \beta_{j k}=0$, the coefficients of the second-order variable in the trans log model are zero. This implies that the Cobb-Douglas function best fits for the for the data.

- $H_{0}: \psi_{1}=\psi_{2} \cdots=\psi_{n}=0$, the null hypothesis states that production risk in input factors does not explain output variability.

- $H_{0}: \lambda=0$, the null hypothesis specifies that inefficiency effects are absent from the model at every level. The variance of the inefficiency term is zero; the exogenous factors should be incorporated into the mean output function and estimated using Ordinary Least Square (OLS). However, if $\lambda>0$, it means that the technical inefficiency effects are present in the model and hence the stochastic frontier model must be employed.

- $H_{0}: \delta_{1}=\delta_{2}=\cdots=\delta_{j}=0$, the null hypothesis states that farm specific factors do not jointly influence technical efficiency in the model.

The entire hypothesis was investigated using the generalized likelihood-ratio statistic (LR) which is given by:

$$
L R=n\left[\ln \left(L\left(H_{0}\right)-\ln \left(H_{1}\right)\right]\right.
$$

Where: $\mathrm{L}\left(\mathrm{H}_{0}\right)$ and $\mathrm{L}\left(\mathrm{H}_{1}\right)$ are values of likelihood function under the null $\left(\mathrm{H}_{0}\right)$ and alternative $\left(\mathrm{H}_{1}\right)$ hypothesis, respectively. LR has approximately a chisquare distribution if the given null hypothesis is true with a degree of freedom equal to the number of parameters assumed to be zero in null hypothesis. The third hypothesis, however, assumes a mixed chi-square suggested by Kodde and Palm (1986). 


\section{Result and Discussion}

In this section, firstly the results of the descriptive analysis were presented. Subsequently, the results of the technical efficiency of maize production and the associated risks were presented.

\section{Descriptive Analysis}

Socio-economic characteristics of sample household: The socio-economic characteristics of the sample households are detailed in the Table 1. The average family size of sample farm households was 7. Out of the sample households, 90 percent are male headed while the remaining 10 percent are female headed. The mean age of the male household heads was 41 years whilst that of their spouses was 34 years. About 93 percent of the sample households were married and living with their spouses, about three percent were widowed, about one percent were married but divorced/separated while about three percent of the sample households were never married during the survey.

About 63 percent of the spouses (wives) are illiterate, while 37 percent of the male household heads were illiterate. The minimum and maximum educational level attained by both husband and wife in the households were 0 and 13 years, respectively. The average years of schooling of household heads are 3.5 years while the mean schools of the wives were 1.3 years.

In the descriptive statistics result, it was found that 52 percent of maize farmers needed credit but couldn't have access to it. Similarly, the average daily contact of extension services is 12 days.

Fertilizer and manure usage/ application and costs: Table 2 summarizes farmers' fertilizers, manure and chemicals applications rates per hectare and their respective costs. It is found that 82 percent of the farmers used inorganic fertilizers on their maize plots. However, only about 61 percent of the farmers applied manure to their maize plot. The average Di-ammonium phosphate (DAP) application rate was $87.5 \mathrm{~kg} / \mathrm{ha}$ while the mean Urea application rate was $99.6 \mathrm{~kg} / \mathrm{ha}$. In terms of usage, about 80 and 59 percent of sample farmers applied DAP and Urea respectively to their maize plot. Similarly, about 56 percent of farmers applied chemicals to their maize plot.
The average cost of DAP fertilizer was 51.32 USD/100kg in the 2009/2010 production year, 34.74 USD/100 kg for urea and 22 Birr/liter for chemicals. This result shows that though DAP is more expensive than urea the usage/application of DAP were higher than that of urea. Moreover, at the time of the survey, the average price of maize was $3.7 \mathrm{Birr} / \mathrm{kg}$ while the average maize seed cost was 565 Birr $/ \mathrm{kg}$.

\section{Econometric Results}

In this section, we present hypothesis testing, the diagnostic statistics, estimates of marginal output risk, determinants technical inefficiency and technical efficiency estimates in maize production.

Hypothesis testing: In Table 3, results for four hypotheses tests are presented. The first null hypothesis that states the suitability of the trans $\log$ for our data is rejected at 0.01 probability level. Rather, Cobb-Douglas form was found to be the best fit. The second null hypothesis which states that production risk in inputs is also absent from the production process and hence rejected at 0.01 probability level. This implies that the conventional inputs are jointly related to production risk. This implies that production risk is a common phenomenon in maize production in Ethiopian.

The third null hypothesis which states absence of technical inefficiency in the model was rejected at 0.01 probability level. As can be observed in Table 4, estimated lambda is 9.6 and significantly different from zero which implies the deviation of observed output from the frontier output due to both technical inefficiency and random noise. However, the variation in output that is explainable by technical inefficacy is relatively larger than that resulted from pure noise component of the composed error term. This makes stochastic frontier model more suitable than the deterministic frontier. The fourth null hypothesis which specifies that exogenous factors and conventional input factors do not jointly explain technical inefficiency is rejected at 0.01 probability level. This shows that the variations in technical efficiency among farmers in Ethiopia are explained by the combined effect of the exogenous variables even though some variables are not significant.

Table 1 Demographic characteristics of sampled farmers*

\begin{tabular}{|c|c|c|c|c|c|}
\hline Characteristics & $\mathrm{NH}$ & Mean & Maximum & Minimum & St.dev \\
\hline Family size & 862 & 7 & 22 & 1 & 2.76 \\
\hline Age of household head & 862 & 41 & 95 & 18 & 13.14 \\
\hline Age of the spouse & 862 & 34 & 75 & 15 & 10 \\
\hline Years of schooling of household head $(\mathrm{HH})$ & 862 & 3.5 & 13 & 0 & 3.38 \\
\hline Years of schooling of HH head's spouse & 845 & 1.3 & 13 & 0 & 2.38 \\
\hline Gender of $\mathrm{HH}$ head ( 1 = male; 0 otherwise $)$ & 862 & 0.9 & & & 0.29 \\
\hline Maize adopters & 862 & 0.87 & & & 0.33 \\
\hline Access to credit ( $1=$ yes; 0 otherwise $)$ & 862 & 0.4 & & & 0.49 \\
\hline Farm size & 862 & 2.4 & 12.5 & .125 & 1.799751 \\
\hline
\end{tabular}

NH: Number of Households, *Source: Own computation, 2017 
Table 2 Fertilizer usage/application and their respective costs*

\begin{tabular}{|c|c|c|c|c|}
\hline Fertilizer/manure usage & Mean & Maximum & Minimum & St.dev \\
\hline Household use inorganic fertilizers ( $1=$ if yes, $0=$ otherwise $)$ & 0.82 & 1 & 0 & 0.382 \\
\hline Household manure use ( $1=$ if yes, $0=$ otherwise $)$ & 0.61 & 1 & 0 & 0.49 \\
\hline Household use DAP ( $1=$ if yes, $0=$ otherwise $)$ & 0.80 & 1 & 0 & 0.39 \\
\hline Household use Urea ( $1=$ if yes, $0=$ otherwise $)$ & 0.59 & 1 & 0 & 0.49 \\
\hline Household use chemical $(1=$ if yes, $0=$ otherwise & 0.56 & 1 & 0 & 0.49 \\
\hline Average DAP rate, $\mathrm{Kg} / \mathrm{ha}$ & 87.55 & 450 & 0.5 & 53.55 \\
\hline Average Urea rate, $\mathrm{Kg} / \mathrm{ha}$ & 99.66 & 733.33 & 4 & 76.29 \\
\hline Average chemical used, Ltr/ha & 2.72 & 291.89 & 0.022 & 16.07 \\
\hline Average price of maize & 3.72 & 3.99 & 3 & 0.31 \\
\hline Oxen cost Birr/day & 22 & 870 & 0 & 90.30877 \\
\hline Labor cost Birr/day & 40 & 3250 & 0 & 155.5834 \\
\hline Seed cost Birr $/ \mathrm{kg}$ & 565 & 4362 & 0 & 519.0209 \\
\hline Chemical cost Birr/ltr & 22 & 1920 & 0 & 131.9499 \\
\hline Urea cost Birr/100kg & 352 & 3200 & 0 & 487.6425 \\
\hline DAP cost Birr/100kg & 520 & 3200 & 0 & 442.5413 \\
\hline Maize price Birr $/ \mathrm{kg}$ & 3.7 & 3.99 & 3.009615 & 0.2842056 \\
\hline
\end{tabular}

*Source: Own computation, 2017

Table 3 Results of hypothesis tests*

\begin{tabular}{l|ccc}
\multicolumn{1}{c|}{ Null Hypothesis } & Test Statistic & Critical value & Decision \\
\hline $\mathrm{H} 0: \beta \mathrm{i}=0$ & $146.5^{* * *}$ & 30.6 & Reject H0 \\
$\mathrm{H} 0: \psi 1=\psi 2=\ldots=\psi 5=0$ & $98^{* * *}$ & 15.1 & Reject H0 \\
$\mathrm{H} 0: \lambda=0$ & $88.5^{* * *}$ & 9.5 & Reject H0 \\
$\mathrm{H} 0: \delta 1=\delta 2=\ldots=\delta 12=0$ & $378^{* * *}$ & 29.1 & Reject H0 \\
\hline
\end{tabular}

*Source: Own computation, 2017; *P<0.1;**P<0.05; *** $\mathrm{P}<0.01$

Table 4 Maximum likelihood estimates of the cobb-douglas mean output function*

\begin{tabular}{|c|c|c|}
\hline Variable & Coefficient & Test Statistic \\
\hline Constant & $9.554(0.103)$ & $92.56^{\text {**: }}$ \\
\hline Log of fertilizer rate & $0.055(0.009)$ & $6.07 * * *$ \\
\hline Log of chemical application & $0.010(0.049)$ & 0.21 \\
\hline Log of seed rate & $-0.054(0.018)$ & $-2.96 * * *$ \\
\hline Log of ox plough days & $0.008(0.032)$ & 0.25 \\
\hline Log of labor use & $0.073(0.021)$ & $3.41 * * *$ \\
\hline $\log$ of $\operatorname{sig}^{2} \mathrm{~V}$ & $-3.974(0.445)$ & $-8.93 * * *$ \\
\hline $\log$ of $\operatorname{sig}^{2} U$ & $0.551(0.067)$ & $8.24 * * *$ \\
\hline Sigma_V & $0.137(0.031)$ & \\
\hline Sigma_U & $1.317(0.044)$ & \\
\hline Sigma $^{\overline{2}}$ & $1.753(0.112)$ & $15.65 * * *$ \\
\hline Lambda $(\lambda)$ & $9.606(0.064)$ & $137.14 * * *$ \\
\hline $\operatorname{Gamma}\left(\lambda=\lambda^{\wedge} 2 /\left(1+\lambda^{\wedge} 2\right)\right)$ & 0.98 & \\
\hline Mean technical efficiency & 0.48 & \\
\hline Maximum TE & 0.95 & \\
\hline Minimum TE & 0.05 & \\
\hline
\end{tabular}

*Source: Own computation, 2017; ${ }^{*}<<0.1 ; * * \mathrm{P}<0.05 ; * * * \mathrm{P}<0.01$, The figures in the parenthesis are corresponding standard errors.

The diagnostic statistics: The estimated sigma square $\left(\sigma_{s}^{2}\right)$ parameter $(1.75)$ and lambda $(\lambda=\sigma \mathrm{u} / \sigma \mathrm{v})$ parameter (9.6) in the stochastic frontier production function are significantly different from zero (Table 4). This indicates a good model fit and the correctness of the specified distributional assumptions. A positive lambda value also implies that the variation in the observed output from the frontier output is due to technical inefficiency and random noise. The variation in output explained by technical inefficiency is relatively larger than that of the composed error term. The value of gamma $(\gamma)$ which is 0.98 is significant at 1 per cent indicating that 98 percent of the total variations in maize output are due to technical inefficiencies in the study area.

Farmers in the study areas exhibited a significant portion of technical inefficiency in maize production. The mean technical efficiency of farmers is found to be 0.48 , which implies the possibility of increasing maize productivity by 52 percent with the existing technology.

We can also apply the concept of elasticity to determine the stage of production in which the maize farmers are operating .The findings of this study show 
that all the output elasticities are significant except for fertilizer. The output elasticity for fertilizer, labor and seed usage are 0.055 percent, 0.073 percent, and -0.054 percent respectively. These results show that an increment in the number of labor employed per hectare by one percent increases maize yield by 0.073 percent while an increment in the amount of seed applied per hectare by one percent decreases maize yield by 0.054 percent, ceteris paribus.

This unexpected significant negative impact of seed usage on maize production could be due to farmers' failure to establish complementarity between the usages of seeds and other production inputs.

The findings of this study indicate that a one percent increase in the quantity of fertilizer applied per hectare will increase the maize output by 0.055 percent. This implies that the fertilizer usage positively influence maize output and the relationship is significant. This result is consistent with the finding of the study by Ahmadu and Alufohai (2012) on the estimation of technical efficiency of rice production under irrigation in Niger state, Nigeria. A subsequent percent increase in other inputs such as chemical application and ox plough days can positively affect maize output but their relationship is not strong. Maize farmers at the study areas operate under diminishing rate of returns to scale because the total elasticity of production is less than one (0.092).

Estimates of marginal output risk: Output variability in the production process has been explained by the input factors that reveal information for production risk management. Some of the inputs are risks minimizing while the others maximize risks and hence provide vital information to stabilize maize output. Estimates for the marginal input risks are presented in Table 5. Fertilizer, chemical application, and ox plough days reduce output variability, although the effect of chemical application is insignificant. Therefore, fertilizer and ox plough days can effectively be used to reduce maize output variability. A risk-averse farmer may go ahead and use more amount fertilizer and ox plough days which in fact reduce risk and the same time maize output as well.

The study also revealed that labor and seed usage rates reduce maize output variability. The significant negative impact of labor on maize output variability is quite consistent with the finding of the study by Villano and Fleming (2006) on technical inefficiency and production risk of rice farming in Central Luzon, the Philippines. In their work, labor was also classified as a risk increasing input. A risk-averse farmer, therefore, employs less number of labor and use less amount of seeds to reduce the variability of maize output. The negative association between seed usage and maize output noted by this study is consistent with the findings of the study by Tadeores and Wall (2003). The effect of an input, however, should not be tied to output variance from the inception; rather it should be an empirical issue (Just and Pope, 1978).

Determinants of maize technical inefficiency: The estimates of the parameters for the determinants of technical inefficiency are presented in Table 6. From the estimates, family size, distance to the nearest market, plot size and use of terracing have positive effects on technical inefficiency. Family size is positively correlated with technical inefficiency as farmers with more number of family members are less efficient. Similarly, plot size has a positive effect on technical inefficiency which testifies the fact that farmers with big plot size could not properly manage their plot and are more inefficient.

Table 5 Maximum likelihood estimates of the linear production risk of maize farms*

\begin{tabular}{l|cc}
\hline \multicolumn{1}{c|}{ Variable } & Coefficient & Test statistics \\
\hline Constant & $1.727(0.264)$ & $6.55^{* * *}$ \\
Fertilizer rate & $-0.022(0.006)$ & $-3.5^{* * *}$ \\
Chemical application & $-6.105(26.765)$ & -0.23 \\
Seed rate & $0.011(0.002)$ & $6.67^{* * *}$ \\
Ox plough days & $-1.232(0.086)$ & $-14.33^{* * *}$ \\
Labor use & $0.006(0.0007)$ & $7.81^{* * *}$ \\
\hline
\end{tabular}

*Source: Own computation 2017; *P<0.1;**P<0.05; ***P<0.01

Table 6 Maximum likelihood estimates of determinants of technical inefficiency*

\begin{tabular}{l|cc}
\hline \multicolumn{1}{c|}{ Variable } & Coefficient & Test statistics \\
\hline Constant & $1.266(0.392)$ & $3.22^{* * *}$ \\
Distance to the nearest market & $0.145(0.078)$ & $1.87^{*}$ \\
Distance to the nearest source of fertilizer dealer & $-0.062(0.021)$ & $-2.94 * * *$ \\
Family size & $0.056(0.021)$ & $2.63 * * *$ \\
Age & $-0.009(0.006)$ & $-1.49^{*}$ \\
Sex & $-0.493(0.258)$ & $-1.91^{*}$ \\
Education & $-0.101(0.022)$ & $-4.63^{* * *}$ \\
Credit access & $-0.239(0.121)$ & $-1.98^{* *}$ \\
Frequency of extension contact & $-0.003(0.001)$ & $-3.15^{* * *}$ \\
Plot size & $0.307(0.188)$ & $1.63^{*}$ \\
Terrace & $0.984(0.206)$ & $4.77^{* * *}$ \\
Soil bund & $-0.791(0.291)$ & $-2.72 * * *$ \\
\hline
\end{tabular}

*Source: Own computation 2017; *P<0.1; **P $<0.05 ; * * * \mathrm{P}<0.01$ 
On the other hand, age, sex, education level, access to credits and frequency of extension contacts are negatively correlated with technical inefficiency. Farmers' age is negatively associated with technical inefficiency as older farmers are more efficient that the younger ones. In the view of Coelli and Battesse (1996), farmers' age could have a mixed effect upon their inefficiencies. These authors conclude that older farmers have more farming experience and hence more efficient. However, it is also possible that older farmers likely use more conservative to adopt new practices. Another school of thought also suggests that old farmers would be less energetic to work on farm and their technical efficiency is lower. The study by Villano and Fleming (2006), noted similar finding whereby age of farmers has significant positive influence on technical efficiency. Farmers' age influence technical efficiency positively only when farmers gain more experience on best farm practices as they grow already which is mostly true. On the other hand, age can influence technical efficiency negatively if the farmers are resistant to adopt best farm practices.

As often claimed by development theories, farmers' access to credit improve farmers' liquidity position and enhance the use of more production inputs. Accordingly, the estimates obtained for the study area indicate that access to credit is statistically significant to negatively influence the technical inefficiency of maize farmers.

The study also revealed that farmers that attained high level of education are technically less inefficient. This can be attributed to a wide array of information available with highly-educated farmers have that can help improve their farming practices and technical efficiency. Empirical studies documented mixed opinions about the effect of education on inefficiency.

In their study, Battesse and Coelli (1995) hypothesized that education is important to increase the farmers' ability to utilize existing technologies and attain higher efficiency levels. On the other hand, Owour and Shem (2009) indicated that educational level is negatively correlated with farmers' technical efficiency. One possible explanation is that technical skills in agricultural practices, particularly in developing countries are more influenced by "hands on" training in modern agricultural methods than just formal schooling. Another study indicated that technical inefficiency tends to increase after 5 years of schooling. This could probably be explained by the fact that high education attenuates the desire for farming as farmers rather concentrate on other non-farm employment (Kibaara, 2005). Ultimately, this reduces labor availability for farm production thereby lowering efficiency.

The model generated coefficient for gender variable indicates that male maize farmers are technically more inefficient. This result agrees with the finding of the study by Kibaara (2005) which found a significant negative relationship between the maize farmers' being males and technical inefficiency of these farmers. This could be explained by the fact that men have greater access to credit, probably because of cultural prejudice, and hence men are closer to the production frontier. In addition, male farmers are most likely to attend agricultural extension training seminars than female farmers (Kibaara, 2005).

The frequency of extension contact is also statistically significant to negatively affect technical inefficiency. According to Alhassan (2008), extension visits enable farmers to use recommended production practices and improve their efficiency. Extension agents are supposed to provide advisory services and training to improve farmers' efficiency. This implies that farmers' interactions with extension agents help them to enhance efficiency. It is a signal that either the extension agents themselves are well trained and so the quality of information needed to increase efficiency is adequate or farmers made enough contacts with these extension officers that can bring a substantial change in efficiency levels. Owens et al. (2003) upon analyzing the impact of extension services on the efficiency of agricultural production in Zimbabwe found that farmer's access to extension services increases the value of output by 15 percent. On the other hand, Alemu et al. (2002) reported an opposite result. The finding of their study revealed that extension visits could not bring about significant reductions in the inefficiency levels. They attributed to the fact that development agents or extension agents remain at the edge, never reaching the farmer and that the training packages may not fit the agro ecological settings. They argued that it is not extension services in terms of visits that makes the difference but the appropriateness of the extension message or training.

Technical efficiency estimates: The technical efficiency estimates range from five percent to 95 percent. About four-fifth (80.6 percent) of the farmers operate with technical efficiency of less than 0.70 . The least technical efficiency range is between 0.05 and 0.10 and about two percent of the farmers fall within this range. The mean technical efficiency is about 48 percent which implies that maize farmers suffer from significant technical inefficiency. This further signal that on the average farmers are 52 percent below the frontier output at the given technology. There is, therefore, possibility to increase maize output in the study area by 52 percent on average in the short run by adopting new and best maize production. The use of best farm practice such as transplanting and proper mechanization can contribute effectively towards the achievement of the frontier output.

The study indicates that the mean efficiency of the farmers is 48 percent, which is very low as compared with the study done by Bäckman et al. (2011) on determinants of technical efficiency of maize farms in north-central and north-western regions in Bangladesh where the mean technical efficiency was estimated as 83 percent. It is also far below the findings of Donkoh et al. (2013) on the technical efficiency of maize production at the Tono irrigation scheme in Northern Ghana where the mean efficiency was also estimated as 81 percent.

In a related study on maize production in the Northern Ghana by Alhassan (2008) the lowest level of technical efficiency for irrigated rice farms was 12 percent, which is higher than our result in which the lowest level of 
technical efficiency is about five percent. The efficiency scores also indicate that an average maize farmer can attain the efficiency level of the most technically efficient maize farm if the farmer can realize 52 percent of cost savings. The most technically inefficient maize farmer should realize a cost reduction of 95 per cent (i.e., 1[0.05]) to achieve the technical efficiency level of those most efficient maize farmers.

\section{Conclusions}

This paper examined the production risk and technical efficiency of maize farmers in three national regional states of Ethiopia, and the associated factors that determinants of production risk and technical inefficiency of these farmers. To achieve the objective of the study Cobb-Douglas form of the model was used.

The finding of the study showed that production risk is jointly explained by labor, fertilizer, seed, ox ploughs and chemical applications. The deviations in output because of technical inefficiency are more pronounced than the deviations in output because of the pure noise component in output. The combined effects of farm specific factors can explain variation in technical efficiency. Maize farms in are operating below the production frontier. This is due to the presence of both production risk and technical inefficiencies in the production process of maize farms in the study areas.

The finding indicates that the conventional input factors such as labor, fertilizer, seed, ox ploughs, and chemical application are important in the maize production process. Fertilizer and ox ploughs decrease the mean output of maize. The input variable labor increases mean output of maize. The production technology characterizing maize farms in the study area exhibits decreasing returns to scale (0.092). Labor and seed are risk increasing inputs. Fertilizer and ox ploughs are risk reducing inputs and hence can be used to mitigate the effect of production risk.

The study concludes that not accounting for production risk in technical efficiency estimations results in biased technical efficiency estimates. The mean technical efficiency for the sample farms is about 48 percent. The existing technical efficiency estimate presents the opportunity to increase maize output by 52 percent without employing additional resources. Highly educated farmers are more efficient. Farmers that have access to credit in the study area are also more efficient.

The study recommends that maize farmers in the study area should increase the use of inputs such as labor, fertilizer and ox ploughs as increasing these inputs has the potential to increase maize output. The amount of seed applied per hectare should be reduced as it is evident that farmers are operating in the third stage of production with respect to seed. Because fertilizer and ox ploughs are risk reducing inputs, the development agents should encourage these maize farmers to properly manage these inputs. This may mitigate the effect of yield variability. Moreover, the extension and advisory services to farmers should be accessed and strengthened in a way that makes farmers more technically efficient. The Ministry should also ensure that at every point in time the extension agents themselves are abreast with current best farm practices. This will affect the quality of information relayed to farmers and will be translated into less inefficiencies in the production system.

\section{References}

Abdulai A, Huffman WE. 2005. The diffusion of new agricultural technologies: The case of crossbred-cow technology in Tanzania. American Journal of Agricultural Economics, 87(3): pp.645-659.

Aigner D, Lovell CK, and Schmidt P. 1977. Formulation and estimation of stochastic frontier production function models. journal of Econometrics, 6(1), pp.21-37.

Alemu BA, Nuppenau EA, Boland H. 2009. Technical efficiency of farming systems across agro-ecological zones in Ethiopia: An application of stochastic frontier analysis. Agricultural Journal, 4(4): 202-207.

Al-Hassan S. 2008. Technical efficiency of rice farmers in Northern Ghana (No. RP_178). African Economic Research Consortium.

Bachewe F. 2009. The state of subsistence agriculture in Ethiopia: Sources of output growth and agricultural inefficiency (Doctoral dissertation, UNIVERSITY OF MINNESOTA).

Bäckman S, Islam KZ, Sumelius J. 2011. Determinants of technical efficiency of rice farms in North-Central and North-Western regions in Bangladesh. The Journal of Developing Areas, 45(1): 73-94.

Battese GE, Coelli TJ. 1995. A model for technical inefficiency effects in a stochastic frontier production function for panel data. Empirical economics, 20(2): 325-332.

Coelli TJ, Battese GE. 1996. Identification of factors which influence the technical inefficiency of Indian farmers. Australian Journal of Agricultural Economics, 40(2): 103-128.

Coelli TJ, Rao DSP, O'Donnell CJ, Battese GE. 2005. An introduction to efficiency and productivity analysis. Springer Science \& Business Media.

CSA. 2013. Central Statistical Agency. Agricultural sample survey, report on farm management practices, private peasant holding. Addis Ababa, Ethiopia, Ethiopia.

CSA. 2014. Central Statistical Agency. Agricultural sample survey, report on farm management practices, private peasant holding. Addis Ababa, Ethiopia.

Donkoh SA, Ayambila S, Abdulai S. 2013. Technical efficiency of rice production at the Tono irrigation scheme in northern Ghana. American Journal of Experimental Agriculture, 3(1): 25.

Just RE, Pope RD. 1978. Stochastic specification of production functions and economic implications. Journal of econometrics, 7(1): 67-86.

Kibaara BW. 2005. Technical efficiency in Kenyan's maize production: An application of the stochastic frontier approach (Doctoral dissertation, Colorado State University).

Kodde DA, Palm FC. 1986. Wald criteria for jointly testing equality and inequality restrictions. Econometrica: journal of the Econometric Society, pp.1243-1248.

Kumbhakar SC. 2002. Specification and estimation of production risk, risk preferences and technical efficiency. American Journal of Agricultural Economics, 84(1): pp.8-22.

Kumbhaker SC. 1993. An Investigation of Production Risk, Risk Preferences and Technical Efficiency', Evidence from Rain fed Lowland Rice Farms in the Philippines.

Meeusen W, van Den Broeck J. 1977. Efficiency estimation from Cobb-Douglas production functions with composed error. International economic review, pp.435-444.

Nawata K, Ii M. 2004. Estimation of the labor participation and wage equation model of Japanese married women by the simultaneous maximum likelihood method. Journal of the Japanese and International Economies, 18(3): 301-315. 
Ogundele OO, Okoruwa V. 2006. Technical efficiency differentials in rice production technologies in Nigeria (No. RP_154). Nairobi: African Economic Research Consortium.

Owens T, Hoddinott J, Kinsey B. 2003. The impact of agricultural extension on farm production in resettlement areas of Zimbabwe. Economic Development and Cultural Change, 51(2): 337-357.

Owuor G, Shem OA. 2009. What are the Key Constraints in Technical Efficiency of Smallholder Farmers in Africa? Empirical Evidence from Kenya. In 111th Seminar, June 26-27, 2009, Canterbury, UK (No. 52807). European Association of Agricultural Economists.

Sanchez PA, Denning GL, Nziguheba G. 2009. The African green revolution moves forward. Food Security, 1(1): 37-44.
Tefaye W, Beshir H. 2014. Determinants of Technical Efficiency in Maize Production: The Case of Smallholder Farmers in Dhidhessa District of Illuababora Zone, Ethiopia. Journal of Economics and Sustainable Development, 5(12): 274-284.

Teklewold H, Kassie M, Shiferaw B. 2013. Adoption of multiple sustainable agricultural practices in rural Ethiopia. Journal of Agricultural Economics, 64(3): 597-623.

Teshome K. 2005. Technical Efficiency of Maize production: A case of smallholder farmers in Assosa Woreda. An MSc Thesis submitted to the School of Graduate Studies, Alemaya University.

Villano RA, Fleming E. 2006. Technical inefficiency and production risk in rice farming: Evidence from the central Luzon Philippines. Asian Economic Journal, 20: 129-46. 